
Case Reports in
Acute Medicine
Case Rep Acute Med 2021;4:13-17

DOI: 10.1159/000513580

Published online: March 8, 2021 (c) 2021 The Author(s)

Published by S. Karger AG, Base www.karger.com/cra

This article is licensed under the Creative Commons Attribution-NonCommercial 4.0 International License (CC BY-NC) (http://www.karger.com/Services/OpenAccessLicense). Usage and distribution for commercial purposes requires written permission.

\title{
Rescue Pericardial Drainage and Return Connected to ECMO for Aortic Rupture into the Pericardial Sac with Acute Type A Aortic Dissection
}

\author{
Shinichi ljuin ${ }^{a}$ Mariko Takeuchib Chikashi Nakaic Akihiko Inoue ${ }^{a}$ \\ So Izumic ${ }^{c}$ Nobuaki Igarashi $^{b} \quad$ Shigenari Matsuyama $^{a}$ Satoshi Ishihara ${ }^{a}$ \\ Tomofumi Doi $^{\mathrm{b}} \quad$ Shinichi Nakayama ${ }^{\mathrm{a}}$ Takuro Tsukube $^{c}$ \\ aDepartment of Emergency and Critical Care Medicine, Hyogo Emergency Medical Center, \\ Kobe, Japan; 'bepartment of Cardiology, Japanese Red Cross Kobe Hospital, Kobe, Japan; \\ 'Department of Cardiovascular Surgery, Japanese Red Cross Kobe Hospital, Kobe, Japan
}

\section{Keywords}

Acute type A aortic dissection - Aortic rupture - Cardiac tamponade - Pericardial drainage .

Extracorporeal membrane oxygenation

\section{Abstract}

We present the first documented case of emergent pericardial drainage and return (PD-R) under extracorporeal membrane oxygenation (ECMO) for the management of aortic rupture into the pericardial sac caused by acute type $A$ aortic dissection (AADA). An 83-year-old woman collapsed during an elective coronary intervention. ECMO was eventually required. Acute accumulation of pericardial effusion with aortic dissection was revealed by echocardiography. Percutaneous pericardial drainage was performed using a drainage line connected to the venous line of the ECMO system to maintain blood flow and blood pressure. After stabilization of the patient's hemodynamics, immediate aortic repair was successfully performed and the patient was discharged with no neurological deficit. In cases of massive amounts of 


\section{Case Reports in Acute Medicine}

ljuin et al.: Rescue PD-R Connected to ECMO for AADA

pericardial drainage and persistent hemorrhagic shock due to aortic rupture with AADA, PD-R connected to ECMO is useful while waiting for aortic repair.

(c) 2021 The Author(s)

Published by S. Karger AG, Basel

\section{Introduction}

Pericardial drainage (PD) is generally required for treatment of patients with cardiac tamponade due to aortic rupture. Controlled pericardial drainage (CPD), in which elevation of blood pressure is prevented by adjusting the amount of drained fluid, has been recognized as a favorable procedure for critical cardiac tamponade with acute type A aortic dissection (AADA) [1-3]. However, in cases of massive accumulation of pericardial effusion because of aortic rupture, $\mathrm{CPD}$ is not sufficient to maintain blood pressure. Here, we report that PD and return (PD-R) connected to extracorporeal membrane oxygenation (ECMO) was effective for the management of cardiac tamponade and hemorrhagic shock due to aortic rupture with AADA.

\section{Case Presentation}

An 83-year-old woman with a history of cerebral infarction was hospitalized with a diagnosis of stenosis in the left anterior descending branch. An elective percutaneous coronary intervention was started using a right radial artery approach; however, catheter engagement was difficult because of the tortuosity of the brachiocephalic artery and ascending aorta. She complained of chest pain, followed by loss of spontaneous respiration and palpable pulsations; therefore, cardiopulmonary resuscitation (CPR) was immediately initiated. Because she did not recover, despite continued CPR, ECMO via the right femoral artery and left femoral vein was started. The time from collapse to the induction of ECMO was $11 \mathrm{~min}$.

Subsequently, tracheal intubation was performed, followed by the appearance of cyanosis of the face and distension of the jugular veins. Transthoracic echocardiography revealed the rapid accumulation of pericardial fluid and aortic dissection in the ascending aorta. The patient then underwent CPD for drainage of bloody fluid. However, because it decreased the circulating blood volume and worsened concomitant hemorrhagic shock, her blood pressure and the blood flow during ECMO remained unstable. Then, the drainage route was directly connected to the venous line of the ECMO system, resulting in a flow rate of $2-2.5 \mathrm{~L} / \mathrm{min}$ (Fig. 1). The hemodynamic state was stabilized by adjusting the ECMO flow via control of the drainage volume of the pericardial effusion, which led to rapid improvement of the cyanosis of her face and the distension of the jugular veins.

Subsequently, computed tomography was performed, which resulted in a diagnosis of AADA with rupture of the ascending aorta (Fig. 2). The patient was transferred to the operating room, with a time from onset to operation of $92 \mathrm{~min}$. The intraoperative findings confirmed the presence of aortic dissection and rupture in the ascending aorta, with an initial tear near the orifice of the left coronary artery and an adventitial tear in the left sinus of Valsalva. Reconstruction of the left sinus of Valsalva and ascending aorta and coronary artery bypass grafting from the aorta to the left anterior descending branch using the saphenous vein graft were performed. The postoperative course was uneventful. The patient had no neurological deficit and was transferred to a rehabilitation hospital 45 days after surgery.

\section{Karger'=}




\section{Case Reports in Acute Medicine}

ljuin et al.: Rescue PD-R Connected to ECMO for AADA

\section{Discussion}

Cardiac tamponade, including aortic rupture into the pericardial sac, is one of the most problematic complications of AADA; it can cause rapid deterioration of the hemodynamic state and may result in shock and cardiopulmonary arrest. Among the complications of AADA, cardiopulmonary arrest caused by cardiac tamponade has the worst outcome [4-6]. Pericardial drainage for AADA management has been abandoned, and drainage should be considered only when it is difficult to maintain hemodynamics by the start of surgery [7]. However, we previously reported favorable results of CPD in the prevention of elevation of blood pressure while adjusting the amount of drained fluid $[1,2]$. Moreover, CPD was evaluated as class IIa in the guidelines of the European Society of Cardiology [8].

We recently reported the efficacy of CPD and return (CPD-R), in which the drained bloody fluid is returned directly to the venous line for increasing the circulating blood volume simultaneously with drainage in some cases [9]. However, in cases of massive accumulation of pericardial effusion because of aortic rupture into the pericardial sac, CPD is not sufficient to maintain blood pressure. In the case reported here, although ECMO was initiated for CPR and CPD was performed, the hemodynamic state of the patient remained unstable until the drainage line was directly connected to the venous line of the ECMO system.

The advantages of the combined use of PD-R and ECMO included the maintenance of hemodynamics by draining the amount of bloody pericardial effusion, the maintenance of ECMO flow, and the rapid reduction of central venous pressure, which may increase perfusion of the brain. One limitation of this method is the possibility of aeration in the ECMO circuit. We prevented aeration with careful deairing with a one-way valve. In addition, because the drainage route was directly connected to the venous line of the ECMO system, air embolism was less likely to occur due to capture of the centrifugal blood pump or gas exchange devices. Another limitation is that there may be a risk of applying a too high negative pressure to the drainage tube. However, measuring the inner pressure of the drainage tube is impossible in the urgent situation. We think that there can be no other way to check high negative pressure than by verifying resistance while aspirating pericardial fluid with a syringe.

This report demonstrates the usefulness of PD-R connected to an ECMO system for patients with a massive amount of pericardial drainage and hemorrhagic shock complicated by AADA. PD-R connected to an ECMO system is useful while waiting for aortic repair in this patient cohort.

\section{Conclusion}

In cases with a massive amount of pericardial drainage and sustained hemorrhagic shock, PD-R connected to an ECMO system is useful for the management of critical cardiac tamponade caused by AADA.

\section{Statement of Ethics}

Written informed consent was obtained from the patient for publication of this case report and any accompanying images.

\section{Karger'"}




\section{Case Reports in Acute Medicine}

\section{Conflict of Interest Statement}

The authors have no conflicts of interest to declare.

\section{Funding Sources}

The authors did not receive any financial support.

\section{Author Contributions}

S. Ijuin was involved in main work, data collection, and manuscript writing. M.T., C.N., A.I., S. Izumi, N.I., S.M., S. Ishihara, T.D., and S.N. were involved in data collection and manuscript revision. T. Tsukube was involved in final revision.

\section{References}

1 Hayashi T, Tsukube T, Yamashita T, Haraguchi T, Matsukawa R, Kozawa S, et al. Impact of controlled pericardial drainage on critical cardiac tamponade with acute type A aortic dissection. Circulation. 2012 Sep;126(11 Suppl 1):S97-101.

2 Nakai C, Izumi S, Haraguchi T, Okada Y, Ijuin S, Nakayama S, et al. Long-term outcomes following controlled pericardial drainage for acute type A aortic dissection. Ann Thorac Surg. 2020 Oct;110(4):1357-63.

3 Honda M, Okamura H, Inoue T, Maekawa T. Avoidance of obstructive shock in patients with acute A type aortic dissection treated by emergency pericardial drainage. JJAAM. 2017;28:55-8.

4 Gilon D, Mehta RH, Oh JK, Januzzi JL Jr, Bossone E, Cooper JV, et al.; International Registry of Acute Aortic Dissection Group. Characteristics and in-hospital outcomes of patients with cardiac tamponade complicating type A acute aortic dissection. Am J Cardiol. 2009 Apr;103(7):1029-31.

5 Bayegan K, Domanovits H, Schillinger M, Ehrlich M, Sodeck G, Laggner AN. Acute type A aortic dissection: the prognostic impact of preoperative cardiac tamponade. Eur J Cardiothorac Surg. 2001 Dec;20(6):1194-8.

6 Murai,T. Aortic Dissection and Sudden Death - Statistical Analysis on 1320 Cases Autopsied at Tokyo-to Medical Examiner Office. Jpn J Leg Med. 1988;42(6):564-77.

7 Hiratzka LF, Bakris GL, Beckman JA, Bersin RM, Carr VF, Casey DE Jr, et al.; American College of Cardiology Foundation/American Heart Association Task Force on Practice Guidelines; American Association for Thoracic Surgery; American College of Radiology; American Stroke Association; Society of Cardiovascular Anesthesiologists; Society for Cardiovascular Angiography and Interventions; Society of Interventional Radiology; Society of Thoracic Surgeons; Society for Vascular Medicine. 2010 ACCF/AHA/ AATS/ACR/ASA/SCA/SCAI/SIR/STS/SVM guidelines for the diagnosis and management of patients with Thoracic Aortic Disease: a report of the American College of Cardiology. Circulation. 2010 Apr;121(13):e266-369.

8 Adler Y, Charron P, Imazio M, Badano L, Barón-Esquivias G, Bogaert J, et al.; ESC Scientific Document Group. 2015 ESC Guidelines for the diagnosis and management of pericardial diseases: the Task Force for the Diagnosis and Management of Pericardial Diseases of the European Society of Cardiology (ESC) Endorsed by: The European Association for Cardio-Thoracic Surgery (EACTS). Eur Heart J. 2015 Nov;36(42):2921-64.

9 Ijuin S, Ishihara S, Haraguchi T, Matsuyama S, Nakayama S, Tsukube T, et al. Efficacy of controlled pericardial drainage return for cardiac tamponade with acute type A aortic dissection. JJAAM. 2020;31:227-32. 
Case Reports in Acute Medicine www.karger.com/cra
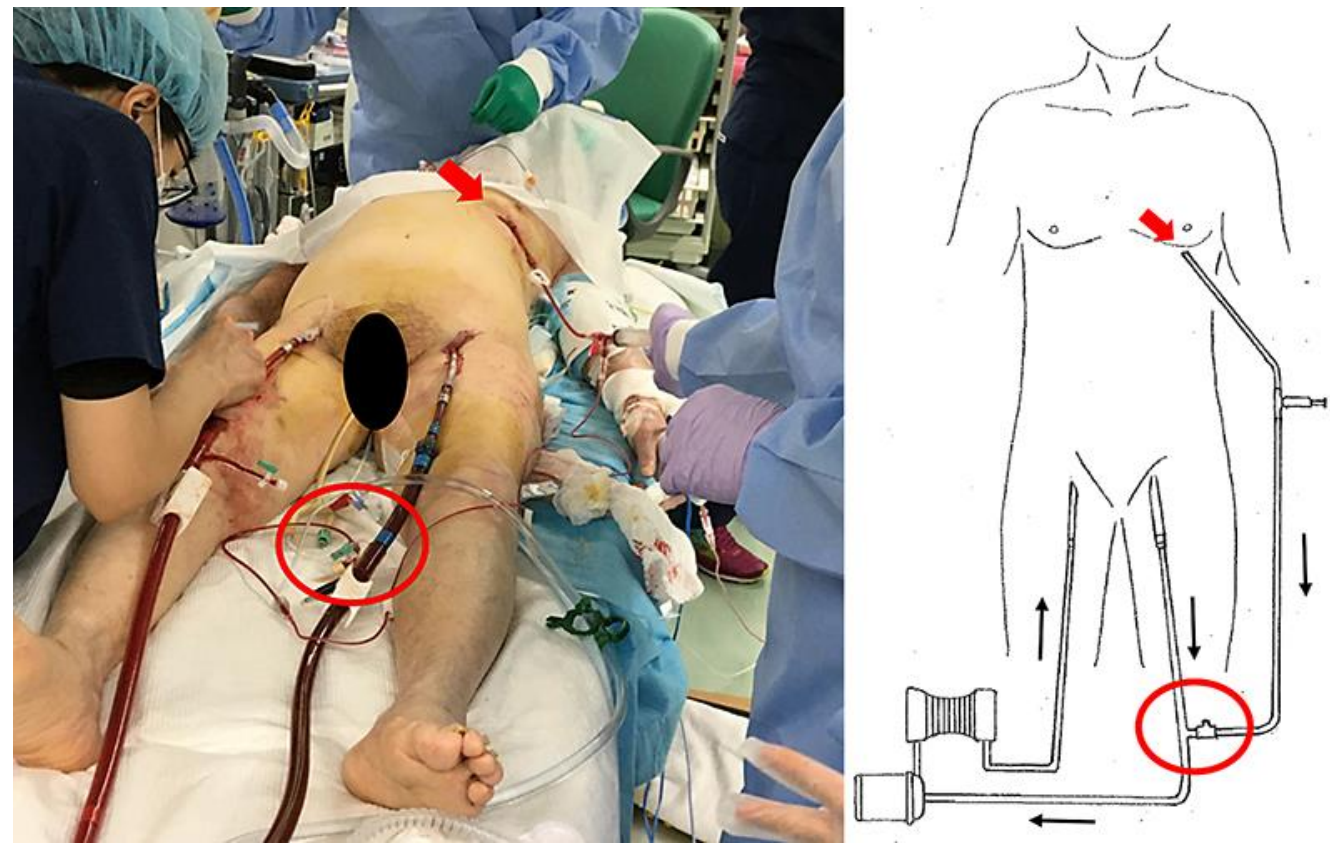

Fig. 1. Controlled pericardial drainage-return connected to an extracorporeal membrane oxygenation (ECMO) system. Pericardial drainage (red arrow) and connection between a pericardial drainage catheter and the ECMO catheter (red circle).
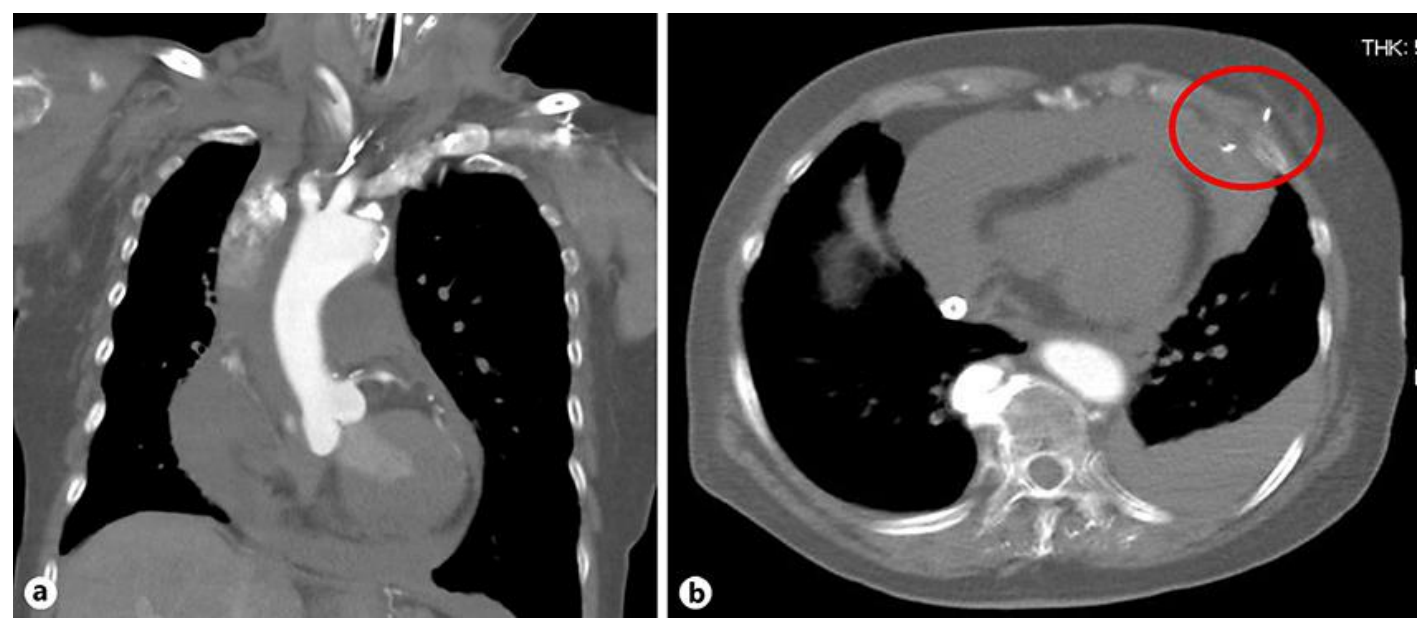

Fig. 2. a Enhanced computed tomography (CT) image showing dissection of the ascending aorta with pericardial effusion. b Enhanced CT image showing the pericardial effusion and a drainage catheter (red circle). 